\title{
Implementation of climate change science in viticulture sustainable development planning in Serbia
}

\author{
Ana Vukovic ${ }^{1}$, Mirjam Vujadinovic ${ }^{1}$, Mirjana Ruml ${ }^{1}$, Zorica Rankovic-Vasic ${ }^{1}$, Zoran Przic ${ }^{1}$, Zoran Beslic ${ }^{1}$, Sasa \\ Matijasevic $^{1}$, Dragan Vujovic ${ }^{1}$, Slavica Todic ${ }^{1}$, Nebojsa Markovic ${ }^{1}$, Branislava Sivcev ${ }^{1}$, Dragoljub Zunic ${ }^{1}$, Ljubomir \\ Zivotic $^{1}$ and Darko Jaksic ${ }^{2}$ \\ ${ }^{1}$ Faculty of Agriculture, University of Belgrade, Nemanjina 6, 11080 Belgrade, Serbia \\ ${ }^{2}$ Ministry of Agriculture, Forestry and Water Management, Nemanjina 22-26, 11000 Belgrade, Serbia
}

\begin{abstract}
Growing interest in Serbia in adaptation of viticulture to climate change emerged from a recorded positive impact of summer increased draught on domestic wine quality. Another motivation is that viticulture has been recognized as one of the fastest developing agricultural sectors in Serbia and, to contain its growing potential, it is crucial to provide basis for its future sustainable development. Prioritization and implementation of adaptation measures in practice require reliable assessment of climate projections. For climate change impact assessment is used high resolution multi-model ensemble of nine regional climate models simulations, bias corrected, with two most probable future scenarios of GHG emissions RCP4.5 and RCP8.5, for the period 2016-2100. Analysis has been done for the near future, mid-century and end of the century periods. The periods are defined according to the IPCC $5^{\text {th }}$ Assessment Report, which enables comparison of climate change impacts with a wider region, and preferably motivate future international collaboration and knowledge exchange.
\end{abstract}

\section{Introduction}

After viticulture has been recognized as one of the fastest developing agricultural sectors in Serbia and probably the only one with positive response to climate change trends over this region, local experts in collaboration with relevant governmental institutions continue to implement latest climate change knowledge in decision-making and promote climate change information among the producers. Increased summer drought [1] had good wine quality response, especially during the years 2012 and 2017, which were critical for other agricultural sectors and caused significant reduction in crop production. Flowering, veraison and harvest advanced significantly [2] because of the change in thermal conditions. Future climate change analysis showed that this trend will continue and accelerate [3], and varieties that are growing in lower altitudes will be under the stress from extreme temperature and late spring frost, which signals the need for advance planning of vineyard displacements and change of selection of varieties in present grape growing areas.

Study presented in this paper is continuation of several studies related to climate change impact on viticulture in Serbia, all using regional climate models results (RCMs) and showing similar signals of climate change relevant to viticulture. The models resolution and complexity of the analysis increased [4-8, 3]. The latest study involved RCP8.5 scenario [9] and analysis of results obtained with one RCM, Non-Hydrostatic Multiscale Model on the B grid (NMMB) on a very high horizontal resolution of about $8 \mathrm{~km}$, with applied bias correction of the results, which is of crucial importance in this application of data [3].

Viticultural zoning performed in Serbia, officially entered into force in 2014 [10], showed diversity in terroir characteristics among wine-growing regions and districts. This, combined with the fact that majority of producers have relatively small scale wine-growing farms, shows necessity for high resolution approach and reliable analysis, since their incomes are highly vulnerable to weather conditions. The latest research on climate change and its impacts on viticulture development and planning, presented in this paper, is implemented according to IPCC $5^{\text {th }}$ Assessment Report (AR5 [9]), using two scenarios, RCP4.5 as lower end and RCP8.5 as higher end scenario, splitting the future period, according to the planning strategy, into three periods: near future, midcentury and end of century. In order to have most reliable results as possible, high-resolution multi-model ensemble approach has been used. Changes of selected climate and bioclimatic indices, which describe climate characteristics relevant for wine-growing regions and 


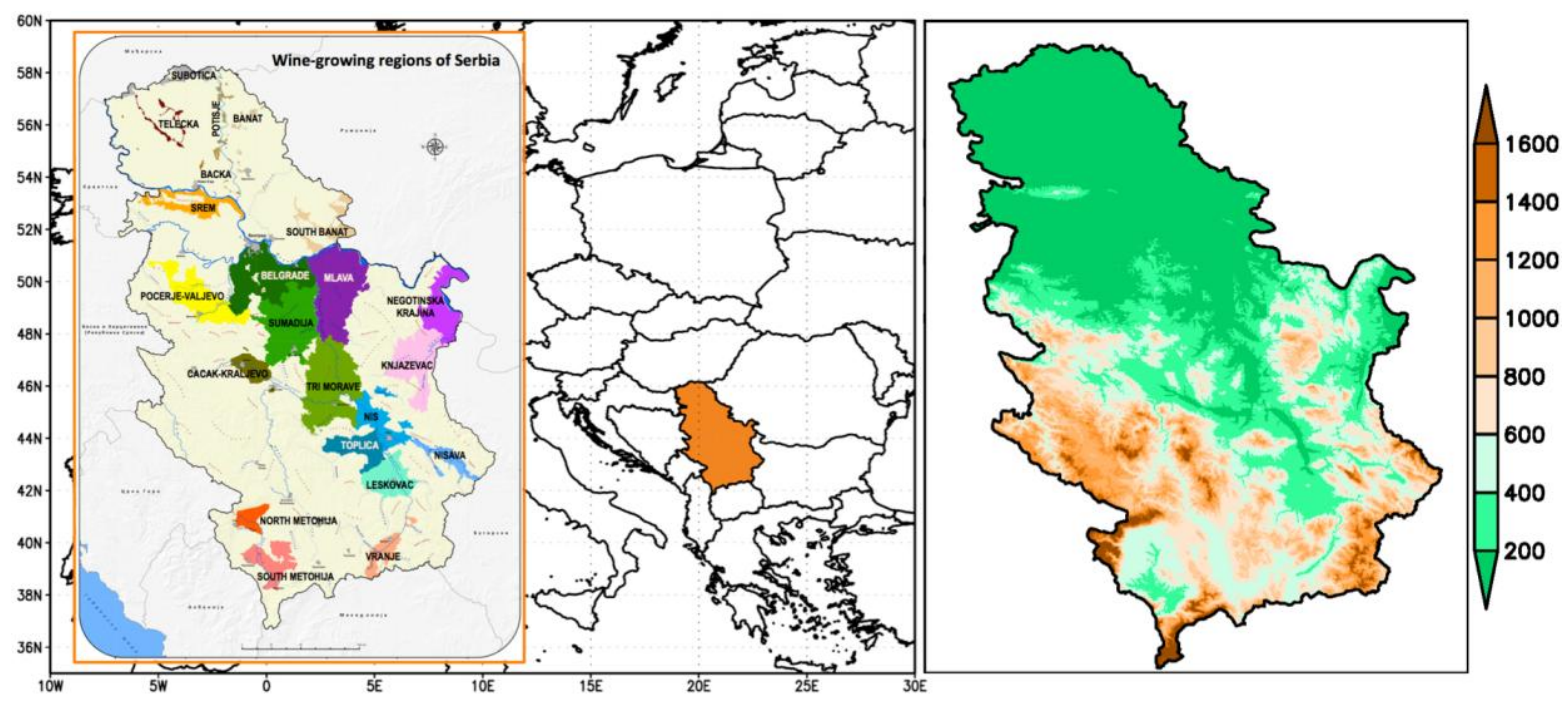

Figure 1. Wine-growing regions in Serbia (left, Viticultural zoning of Serbia, 2014; Vujadinovic et al, 2016) and terrain altitude in meters above sea level (right).

potentials risks, are tested for a degree of confidence to recognize anthropogenic global warming impact on climate change in Serbia and focus the vulnerability and risk assessment in viticulture sector on these extremes. Selection of scenarios and periods, and definition of present climate period 1986-2005, as in IPCC AR5, enables the comparison of the results for Serbia with wider region and possibility for cross-border collaboration and exchange of expertise.

\section{Datasets and methodology}

For future climate analysis are used results of nine RCMs from EURO-CORDEX, bias corrected, with resolution of $0.11^{\circ}$. Multi-model ensemble median values are chosen as representative results. Statistical significance evaluation of climate variables change is done using " $t$ test". If more than half of ensemble members have significant change, than it is considered with certainty that future change is far beyond natural variability. As mentioned before, analysis of the future climate change is divided in periods: 2016-2035 (near future), 2046-2065 (mid-century) and 2081-2100 (end of century), and chosen scenarios are RCP4.5 (stabilization scenario as lower end scenario) and RCP8.5 (constant increase as higher end scenario). For reference period is chosen 1986-2005, as present climate period, and E-OBS gridded daily datasets of temperature and precipitation are used, originally available on $0.25^{\circ}$ but re-gridded on models resolution $0.11^{\circ}$.

Climatological indices relevant for viticulture $[11,12$, 3], chosen for analysis in this paper are: Winkler index (WI), Huglin Index (HI), Cool night index (CI), Dryness index (DI), number of days with maximum temperature above $35^{\circ} \mathrm{C}$ (TX35), and number of dry days during the vegetation period April-October (DD).

Wine-growing regions in Serbia (Figure 1) are distributed mainly within central part of Serbia, where is hilly and mountain region with river basins, which is in contrast to northern part that is flat with altitudes lower than $100 \mathrm{~m}$ and vineyards sparsely distributed. Other parts of Serbia are on higher altitudes and still with unsuitable climate for wine-growing.

\section{Results and discussion}

Future change of temperature and precipitation over Serbia (not shown here) comparing to present climate, according to RCP4.5 and RCP8.5 scenarios, show that: during the near future period mean temperature change will be within the interval $0.5-1.5^{\circ} \mathrm{C}$, during the midcentury $1-3^{\circ} \mathrm{C}$, and during the end of the century $1.5-5^{\circ} \mathrm{C}$, with more pronounced increase over central and southern parts (lower thresholds are obtained with RCP4.5 and higher values are obtained according to RCP8.5); precipitation changes show increase of annual values by the mid-century, and during the second half of the century decrease over central and southern parts up to $20 \%$ according to RCP8.5; most critical change is obtained for summer season, when maximum temperature change is over $5^{\circ} \mathrm{C}$ in central and southern parts of Serbia, and significant precipitation reduction over the whole country, with values of decrease from $10 \%$ to $30 \%$ (according to RCP8.5), intensifying from north to south.

In Figure 2 are presented values for the present climate 1986-2005 of all selected indices. In Figure 3 and Figure 4 are presented values for three future periods, according to $\mathrm{RCP} 4.5$ and $\mathrm{RCP} 8.5$, respectively. In present climate within wine-growing regions HI values show that climate is temperate and temperate warm, with very cool nights according to CI, and sub-humid according to DI. During the near future period climate is changing in a way that within wine-growing regions prevail temperate warm climate over a wider area, with cool nights, and stays in sub-humid category. During the mid-century period temperate warm climate is spatially spreading over Serbia and in northern parts changing to warm category according to RCP4.5, and according to RCP8.5 warm climate also enters central parts of the country. Temperate nights category will appear over 
Belgrade region, and will spread over northern parts in case of RCP8.5. DI shows decrease toward moderately dry category. During the second part of the century GHG emissions stabilize according to RCP4.5, climate change will continue, but with decreased intensity comparing to RCP8.5, which predicts further increase of GHG. In case of long term planning, analyzing end of the century period, it should be considered that present wine-growing regions will have warm climate or, in higher end case scenario, very warm climate, but current heat conditions will spread outside presently defined wine-growing regions. It is highly possible for present wine-growing regions to enter temperate nights category, and major part of the country to experience change of water availability toward moderately dry category.

Analysis of WI, T35 and DD shows that in present climate wine-growing regions are in II and III zone according to WI, T35 has values up to 5, and DD mainly 150-165. During the near future period all present winegrowing regions enter III zone, T35 increases up to 10 , in central parts over 10 , and DD is slightly increasing. During the mid-century period northern parts will enter IV zone, and it is possible that other wine-growing regions experience the same change in case of RCP8.5. $\mathrm{T} 35$ is possible to increase over 15 in some wine-growing regions, especially in central parts. DD values show increased risk of drought in vegetation period. By the end of the century RCP4.5 show the same direction of change but significantly reduced intensity of change, while according to RCP8.8 wine-growing regions enter $\mathrm{V}$ zone, values of $\mathrm{T} 35$ exceed 30 , and $\mathrm{DD}$ shows significant increase of days without rain over the whole Serbia, even with 20-30 days more than in present climate.

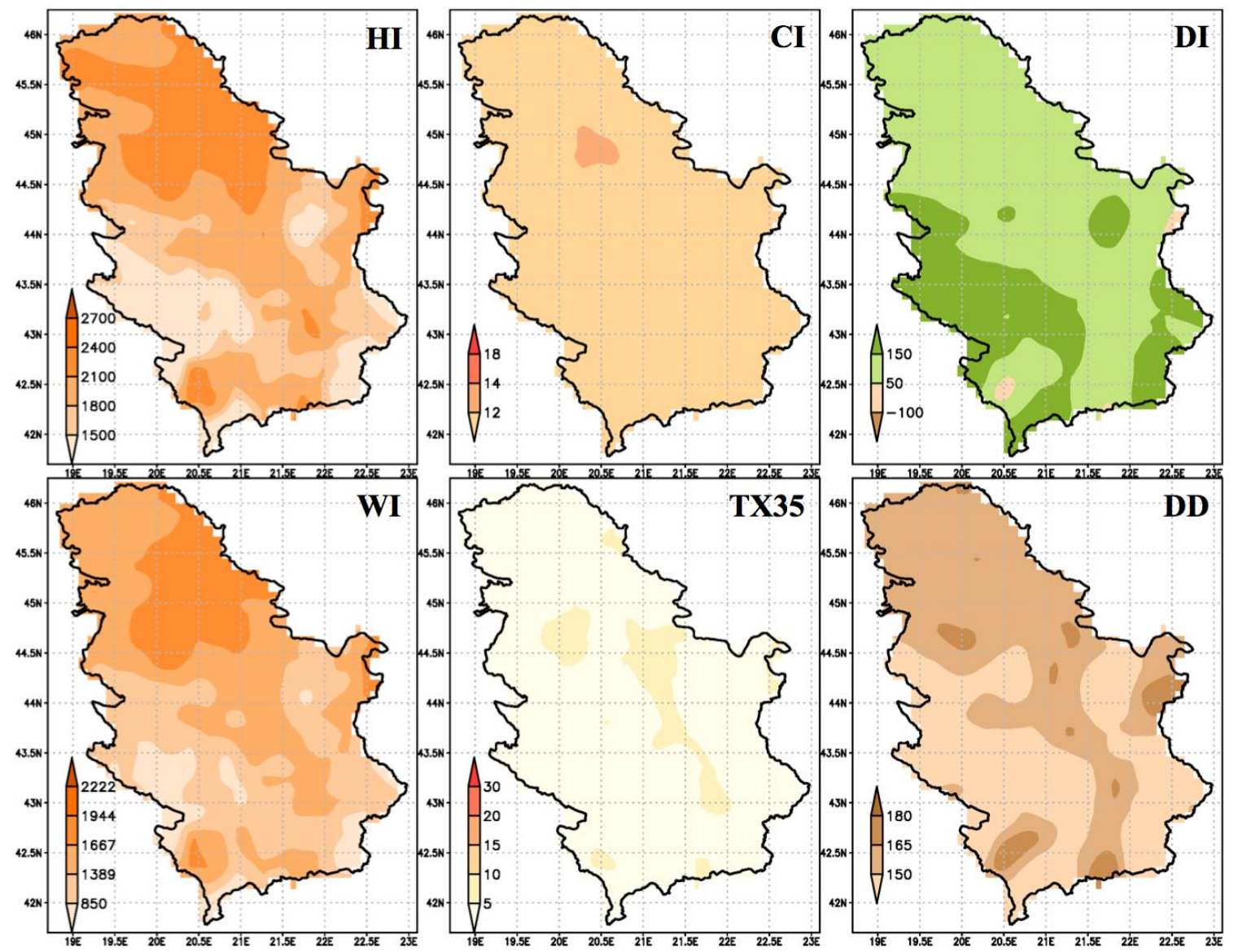

Figure 2. Present climate 1986-2005 values for HI (upper left), CI (upper middle), DI (upper right), WI (lower left), T35 (lower middle) and DD (lower right). 

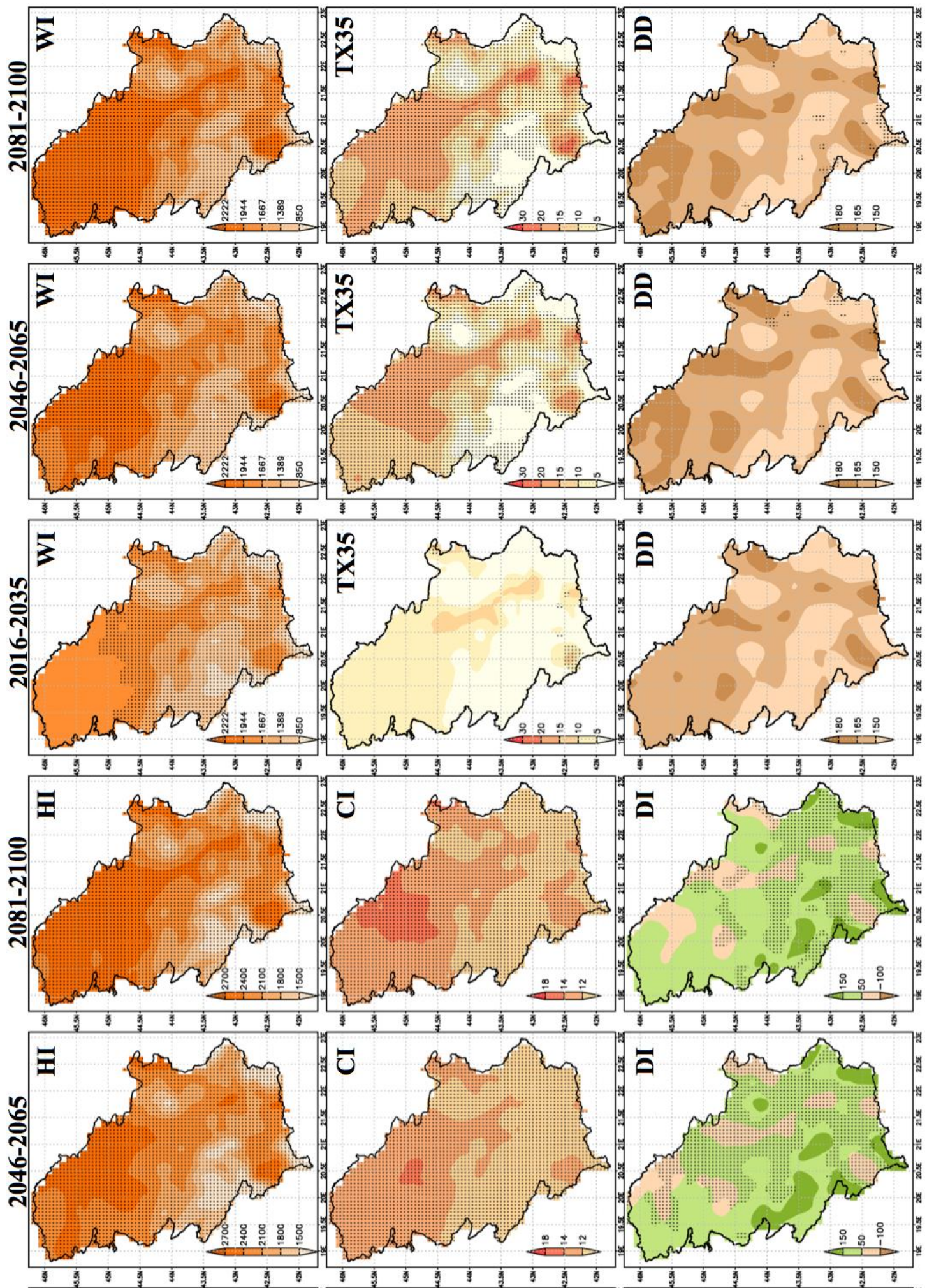

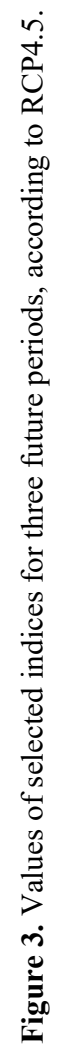




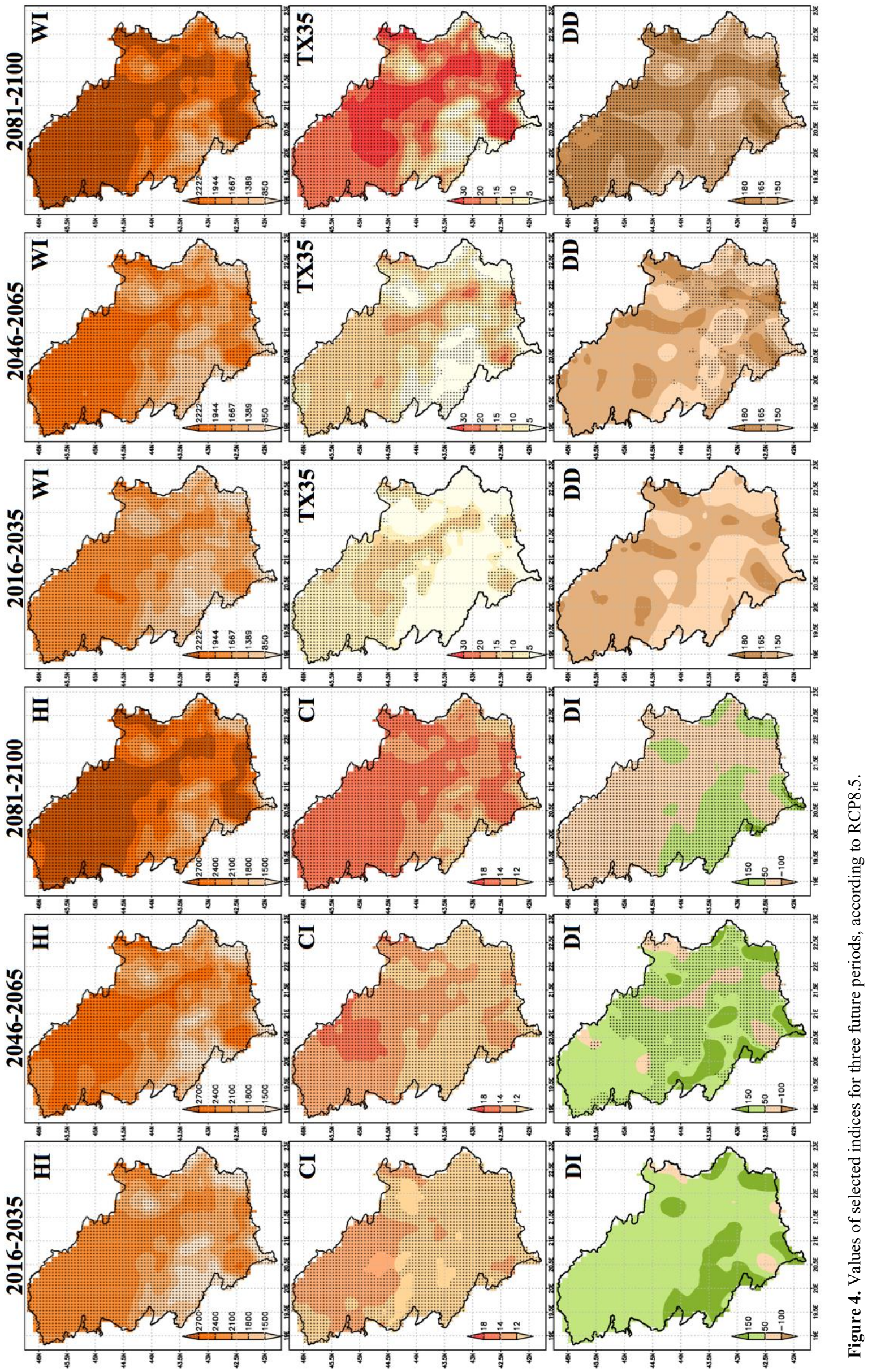




\section{Conclusions}

Results discussed in this paper represent reliable base for planning of adaptation measures and mitigation of climate negative impacts on different time scales, concerning applied methodology. Wine-growing regions will gain heat conditions favorable for high production of good quality wines during the next decades, with appropriate implementation of agro-technical measures, but further in the future risk of high temperatures and significant lack of water in some regions will force displacement of wine-growing regions. Presented results prove the need for frequent change of wine-growing policy carried out through regular update of viticultural zoning, which will ensure sustainable development for this sector of economy. More detail and comprehensive analysis will be implemented through the following, third, National Communication of Republic of Serbia.

\section{References}

1. MEP, The Second National Communication on Climate Change under the United Nations Framework Convention on Climate Change (Ministry of Environmental Protection, Belgrade, Serbia, 2017)

2. M. Ruml, N. Korac, M. Vujadinovic, A. Vukovic, D. Ivaniševic, J Agric. Sci. 154(2), 186-206 (2016)

3. M. Vujadinovic, A. Vukovic, D. Jaksic, V. Djurdjevic, M. Ruml, Z. Rankovic-Vasic, Z. Przic, B. Sivcev, N. Markovic, B. Cvetkovic, P. La Notte P., XI Terroir Congress, Willamette Valley, Oregon, USA (2016)
4. Vukovic, M. Vujadinović, V. Djurdjević, Z. Ranković-Vasić, N. Markovic, Z. Atanackovic, B. Sivčev, N. Petrović, VIII International Terroir Congress, Soave, Italy (2010)

5. M. Ruml, A. Vukovic, M. Vujadinovic, V. Djurdjevic, Z. Rankovic-Vasic, Z. Atancakovic, B. Sivcev, N. Markovic, S. Matijasevic, N. Petrovic, Agric. For. Meteorol. 158, 53-62 (2012)

6. M. Vujadinovic, A. Vukovic, V. Djurdjevic, Z. Rankovic-Vasic, Z. Atanackovic, B. Sivcev, N. Markovic, N. Petrovic, Acta Horticulturae 931, 8794 (2012)

7. Vukovic, M. Vujadinovic, V. Djurdjevic, B. Cvetkovic, Z. Rankovic-Vasic, Z. Przic, M. Ruml M, A. Krzic, Proceedings of the $7^{\text {th }}$ International Conference on Information and Communication Technologies in Agriculture, Food and Environment, Kavala, Greece, 892-901 (2015)

8. Vukovic, M. Vujadinovic, M. Ruml, Z. Przic, Z. Rankovic-Vasic, B. Cvetkovic, V. Djurdjevic, A. Krzic, Third Balkan Symposium on Fruit Growing, Belgrade, Serbia (2015)

9. IPCC, Climate Change 2013: The Physical Science Basis. Contribution of Working Group I to the Fifth Assessment Report of the Intergovernmental Panel on Climate Change (Cambridge University Press, New York, USA, 2013)

10. D. Ivanisevic, D. Jaksic, N. Korac, Atlas of Viticulture (in Serbian) (Statistical Office of the Republic of Serbia, Belgrade, Serbia, 2015)

11. J. Tonietto, A. Carbonneau, Agric. For. Meteorol. 124, 81-97 (2004)

12. A.J. Winkler, J.A. Cook, W.M. Kliwe, L.A. Lider, General viticulture (University of California Press, California, USA, 1974) 